\title{
Fine-scale spatial genetic structure in a predominantly selfing plant: role of seed and pollen dispersal
}

\author{
S Volis, M Zaretsky and I Shulgina \\ Life Sciences Department, Ben-Gurion University of the Negev, Beer Sheva, Israel
}

\begin{abstract}
We present a study of fine-scale spatial genetic structure (SGS) and assess the impact of seed and pollen dispersal on the pattern of genetic diversity in the predominantly selfing Hordeum spontaneum. The study included (1) direct measurement of dispersal in a controlled environment, and (2) analyses of SGS and estimation of the ratio of pollen to seed flow in three natural populations sampled in linear transects at fixed increasing inter-plant distances. Analysis of SGS with 10 nuclear SSRs showed in all three populations a significant autocorrelation for the distance classes of 1 or $2 \mathrm{~m}$ and a negative linear relationship between kinship coefficients, calculated for pairs of individuals, and logarithm of
\end{abstract}

geographical distance between members of the pairs. Major seed dispersal $(95 \%)$ was found to be within $1.2 \mathrm{~m}$ from the mother plant. Pollen flow, estimated from the comparison of nuclear and chloroplast variation, was spatially limited as much as was seed dispersal, and tended to be overestimated when measured at spatial scales exceeding that of SGS. We conclude that combined effects of selfing, occasional outcrossing, localized seed dispersal and high plant density create an equilibrium between drift and gene flow in this species resulting in SGS at a very fine spatial scale.

Heredity (2010) 105, 384-393; doi:10.1038/hdy.2009.168; published online 2 December 2009

Keywords: gene flow; neighborhood size; pollen flow; spatial genetic structure; wild barley

\section{Introduction}

In the past decade, several indirect methods to quantify gene dispersal in a continuously distributed population have been proposed (Epperson and Li, 1997; Hardy and Vekemans, 1999; Rousset, 2000; Hardy, 2003, 2006; Heuertz et al., 2003; Vekemans and Hardy, 2004). In these methods, gene dispersal distance among individuals is inferred through the usage of either inter-individual genetic distance (Rousset, 2000) or relatedness (Hardy and Vekemans, 1999). Limited gene dispersal is inferred from lower genetic distance or higher relatedness among neighboring as compared with more distant individuals. Limited gene flow, according to the concept of isolation by distance (IBD), results in the creation of spatial genetic structure (SGS).

Gene flow in plants has two components, seed and pollen dispersal. Using nuclear and chloroplast molecular markers (Petit et al., 1993; Ennos, 1994), the relative contribution of these two components to gene flow has been estimated in a number of SGS studies embracing a variety of life histories and breeding types (reviewed in El Mousadik and Petit, 1996; Ouborg et al., 1999; Raspe et al., 2000). The vast majority of these studies were done on outbreeding species and showed, in general, a much higher than unity ratio of pollen-to-seed flow. However, in predominantly selfing species, the latter may not be

Correspondence: $\operatorname{Dr} S$ Volis, Life Sciences Department, Ben-Gurion University, PO Box 653, Beer Sheva 84105, Israel.

E-mail:volis@bgu.ac.il

Received 19 May 2009; revised 5 October 2009; accepted 2 November 2009; published online 2 December 2009 true because of the lower incidence of inter-plant pollen transfer. In addition, the contribution of seed and pollen to SGS may change with the distance at which SGS is estimated, and this change may differ between outcrossing and selfing species.

We present a study of fine-scale SGS and assess the effect of seed and pollen dispersal on the pattern of genetic diversity in the predominantly selfing Hordeum spontaneum Koch. This species has been intensively studied for the extent and structure of genetic diversity at a wide range of spatial scales from tens to hundreds and even thousands of kilometers (Brown et al., 1978a; Turpeinen et al., 2001, 2003; Volis et al., 2001b, 2002a, 2003, 2005; Morrell et al., 2003). At large geographical scale, selection and colonization history are predominant evolutionary forces, and a great deal of information about these processes has been gained for wild barley. However, surprisingly little is known in this species about processes that operate at a fine spatial scale, that is, within populations. At this scale, the prevailing forces are genetic drift and gene flow, and the theory of IBD predicts creation of SGS at the drift-dispersal equilibrium. H. spontaneum is an ideal species for studying the contribution of seed and pollen dispersal to the SGS in a predominant selfer because (i) many molecular markers are available, including chloroplast and nuclear SSRs, and (ii) this species often shows almost continuous distribution, which allows sampling at specified distances. Our study employed three approaches: (1) direct measurement of seed dispersal in a controlled environment; (2) analyses of SGS in three natural populations representing different ecological conditions, and sampled 
along linear transects at fixed increasing inter-plant distances; and (3) estimation of the ratio of pollen/seed dispersal in the three populations.

\section{Materials and methods}

\section{Study species}

H. spontaneum Koch (wild barley) is a predominantly autogamous (>98\%) (Brown et al., 1978b) winter annual grass. In Israel, it is one of the dominant annual components of open park forests and Mediterranean grassland, but also of the less favorable Judean and Negev deserts where it occupies ephemeral river valleys (wadis) (Harlan and Zohary, 1966). The abundance of $H$. spontaneum decreases sharply from mesic Mediterranean to arid desert environments, but population density within the wadis is often high due to accumulating runoff from the adjoining hillsides (Volis et al., 2004). The seed dispersal unit has three spikelets, with the central spikelet containing a single caryopsis. Seed dispersal on maturation is reported to be restricted to the immediate vicinity of the mother plant (Gutterman, 1992), but this has not been directly tested. After disarticulation, a spikelet acts as a drill-type dissemination device. Fallen spikelets are either impaled in the dry remnants of the dead mother plant (Gutterman, 1992) or penetrate into soil cracks under the combined effects of wind and gravity. Some spikelet dispersal also occurs by entrapment in the fur of animals.

\section{Sampling}

Importance of design and spatial scale at which sampling is done in SGS studies has been recognized (Epperson and Li, 1996; Hamilton and Miller, 2002; Leblois et al., 2003; Vekemans and Hardy, 2004; Cavers et al., 2005). Both exhaustive sampling within a confined area and sampling at equal distances along linear transects or at each node of a regular grid have been criticized as biased in scale coverage (Vekemans and Hardy, 2004). We used a potentially more effective sampling strategy in which (i) distance classes had the same sample size over transects and populations, and (ii) very small and relatively large spatial scales were equally well represented.

Our study was conducted at three locations in Israel separated by more than $100 \mathrm{~km}$, and which represented three distinct environments and vegetation communities: desert (SB), shrub and semi-shrub association called batha (BG), and Mediterranean grassland (AM) (for details see Volis et al., 2002b). The locations differed in their position within the species range, $\mathrm{SB}$ representing the species periphery, and AM and BG the core. A diagram of our sampling scheme is shown in Figure 1. At each location a single spikelet (=seed) was collected during March-April 2001 in nine linear transects at fixed distances $(0,1,2,5,10,20,50,100$ and $400 \mathrm{~m}$, except for the BG site where the $400 \mathrm{~m}$ distance class was not collected). The transects within each location were separated by at least $100 \mathrm{~m}$. For genetic analysis, seeds were germinated and grown to the two-leaf stage.

\section{Population demography}

Average adult plant density was estimated in two of the three populations (SB and BG) during 1996-1999. In 1996, six transects, distributed $20 \mathrm{~m}$ apart along a slope, were marked in the BG location. Five $1 \mathrm{~m}^{2}$ plots $1 \mathrm{~m}$ apart were permanently marked along each transect. At this site, the distribution of $H$. spontaneum, despite high variation in abundance, was more or less continuous. At the SB location, barley distribution was patchy and discontinuous, and neither transects nor equidistant spacing was possible. Therefore, $1 \mathrm{~m}^{2}$ plots were marked in 1996 in barley patches. Altogether, 30 and 50 plots were marked

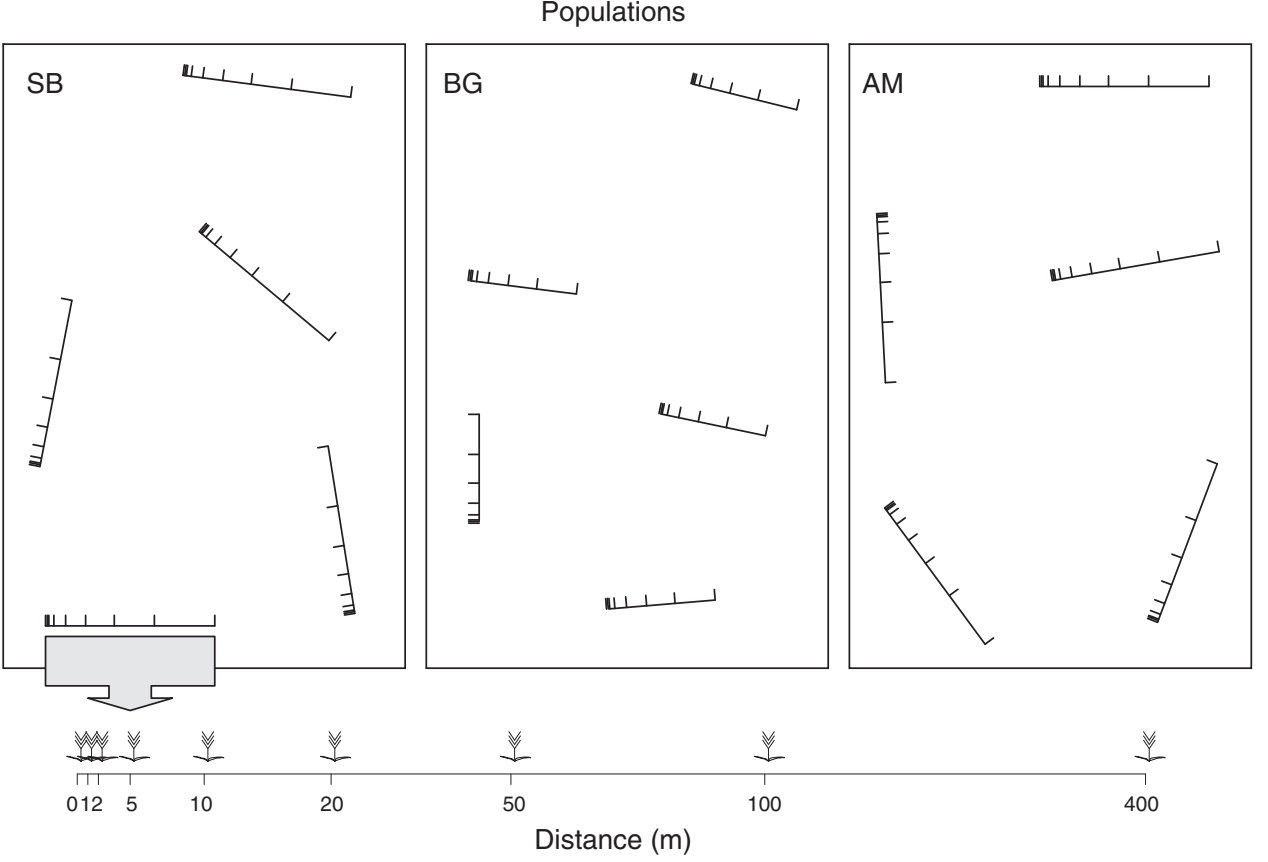

Figure 1 Diagrammatic representation of the sampling scheme. In one population location (BG), sampling was done in the linear transects of $100 \mathrm{~m}$, whereas in the other two population locations the transects were $400 \mathrm{~m}$ long. 
at the BG and SB locations, respectively. We installed a higher number of plots at the SB location because of greater spatial heterogeneity at this location. During the next 4 years, adult plants were counted in each plot. In 1999 , because of very low rainfall, no plant reached adult stage in the SB population and there was no estimate of plant density.

\section{Seed dispersal experiment}

In order to estimate the roles of wind and gravity on wild barley seed dispersal distance, we randomly chose two genotypes from two populations that differed the most in individual seed size and weight (SB and AM). These genotypes were planted in 2006 in a common environment. Seeds of each of these self-pollinated genotypes had a high chance of being genetically identical. Next season, two seeds per genotype were germinated and planted in 15-1 buckets in a commercial potting mixture. One plant per genotype was placed on a flat clean surface in a greenhouse, and another one in a nethouse at the Campus Bergman of Ben Gurion University, Beer Sheva. The space around each plant was divided into circles of $20 \mathrm{~cm}$ width. Upon maturation of spikelets and start of shattering, plants were visited daily for the collection of shattered spikelets within respective distance classes. After plant senescence, we counted the number of spikelets per distance class. The AM plant placed in a greenhouse was infected by leaf rust and produced very few spikelets. Therefore, we present results for SB greenhouse, SB nethouse and AM nethouse plants (841, 811 and 345 seeds, respectively).

\section{Microsatellite analysis}

All plants, 234 in total, were genotyped. DNA extraction followed modified CTAB protocol of Rogers and Benedich (1985). Ten polymorphic nuclear and 5 chloroplast microsatellite loci (Table 1), used to estimate seed and pollen dispersal, respectively, were amplified using PCR according to Schuelke (2000), but with several modifications. The PCR was performed in two steps. The first step was performed with gene-specific primers using the optimal annealing temperature for each primer pair. This was repeated for 10 cycles in order to obtain a specific product. The fluorescent-labeled M13(-21) primer was then added, and the reaction was continued for 25 additional cycles at the annealing temperature of $53^{\circ} \mathrm{C}$. Four different fluorescent M13 primers were used: FAM, NED, PET and VIC. The PCR products were detected and sized by the ABI PRISM 3700 DNA Analyzer (Applied Biosystems, Foster City, CA, USA) at the Hebrew University (Jerusalem, Israel). The data were analyzed using Peak Scanner Software v1.0 (Applied Biosystems).

\section{Data analysis}

The distances between sampled seeds were the exact one-dimensional coordinates for each sampled plant. Therefore, the pairwise genetic distances/relatedness coefficients were obtained for each transect separately.

For the analysis of spatial autocorrelation, the multivariate procedure of Smouse and Peakall (1999) and Peakall et al. (2003) was used, which allowed combining data from separate populations. The statistical significance of autocorrelation was tested for each sampling distance (from 1 to $400 \mathrm{~m}$ ) by performing 1000 random permutations and obtaining 95\% confidence intervals (CIs) after bootstrapping (1000 repeats). The analysis was run for each population separately and over the three populations together using GENALEX 6.0 software (Peakall and Smouse, 2006).

We calculated the kinship coefficients for all pairs of individuals in transects using the statistic of Ritland (1996) as implemented in GENALEX (Peakall and Smouse, 2006). In a comparative study of Vekemans and Hardy (2004), Ritland's estimator proved to be the most powerful for highly polymorphic markers. For each population, the average kinship coefficients across transects were calculated for each distance class and supplied with approximate confidence intervals as twice the standard error estimates obtained by jackknifing over transects. To estimate the regression slopes (b), the multilocus kinship coefficients for all pairs of individuals were plotted against the logarithm of geographic distance separating member of the pair. The extent of gene dispersal was estimated from this slope as $N b=-\left(1-F_{0}\right) / b$, where $N b$ is the neighborhood size in the number of individuals in a continuous two-dimensional population (Wright, 1943), and $F_{0}$ is the average kinship coefficient between adjacent individuals. We estimated $F_{0}$ for the first distance class $(1 \mathrm{~m})$ as the closest approximation to 'adjacent' plants (Vekemans and Hardy, 2004; Oddou-Muratorio and Klein, 2008) and designated it $F_{(1)}$. The lower and upper bounds for the $95 \%$ CIs of $\mathrm{Nb}$ were computed as $\left(F_{(1)}-1\right) /\left(b \pm 2 \mathrm{SE}_{b}\right)$, where $\mathrm{SE}_{b}$ was the standard error of the regression slope $b$ (Hardy et al., 2006). We also calculated the 'S $p$ ' statistic, which is the inverse of the neighborhood size $\mathrm{Nb}$ under IBD in the two-dimensional space (Vekemans and Hardy, $2004)$, that is, the ratio $-b /\left(1-F_{(1)}\right)$. This statistic is very useful in the comparison of SGS and gene dispersal among populations and species.

$\mathrm{Nb}$ and $\mathrm{Sp}$ are most reliably estimated at distances between $\sigma$ (mean gene dispersal distance) and 10-50 $\sigma$ in the two-dimensional space (Rousset, 1997, 2000; Vekemans and Hardy, 2004). At this spatial scale, the drift-dispersal equilibrium establishes within a few generations, and mutations with $\mu<10^{-3}$ can be neglected (Vekemans and Hardy, 2004). Because of the very fine SGS detected, we used a distance range of $\sigma-20 \sigma$ as appropriate for the detection of SGS (Vekemans and Hardy, 2004). We computed the slope $b$ for the full and limited (up to $20 \mathrm{~m}$ ) distance ranges in each population. From these values, we obtained two indirect estimates of neighborhood size and its inverse $(S p)$ for each population.

Gene dispersal under the migration-drift equilibrium was estimated in each population as the standard deviation of gene dispersal distance, $\sigma=\left(\mathrm{Nb} /\left(4 \pi D_{\mathrm{e}}\right)\right)^{0.5}$, where $D_{\mathrm{e}}$ is effective population density. The effective density was estimated from the adult population density, $D$, using the approximation, $D \times N_{\mathrm{e}} / N$ (the ratio of effective to census population size) (Hardy et al., 2006). Under self-fertilization, $N_{\mathrm{e}}$ is predicted to equal $N(2-s) /$ 2 (Pollak, 1987). Thus, in a predominantly selfing species, $N_{\mathrm{e}} \approx N / 2$. On the other hand, the $N_{\mathrm{e}} / N$ ratio in adult plant populations can be as small as 0.1 (Frankham, 1995). Therefore, the estimation of $\sigma$ employed two $D_{\mathrm{e}}$ values, $D / 2$ and $D / 10$. The $95 \%$ CI of $\sigma$ was calculated as $\left(\mathrm{Nb} /\left(4 \pi D_{\mathrm{e}}\right)\right)^{0.5}$ using the upper and lower $\mathrm{Nb}$ bounds from Table 2 . 
Table 1 Repeat type, chromosomal location and statistics of genetic diversity of SSR loci in the three populations

\begin{tabular}{|c|c|c|c|c|c|c|c|c|c|c|c|c|c|c|c|}
\hline \multirow[t]{3}{*}{ Locus } & \multirow{3}{*}{$\begin{array}{l}\text { Repeat } \\
\text { type }\end{array}$} & \multirow[t]{3}{*}{ Reference } & \multirow{3}{*}{$\begin{array}{c}\text { Chromosomal } \\
\text { location }\end{array}$} & \multicolumn{12}{|c|}{ Populations } \\
\hline & & & & \multicolumn{4}{|c|}{$S B(\mathrm{n}=81)$} & \multicolumn{4}{|c|}{$B G(\mathrm{n}=72)$} & \multicolumn{4}{|c|}{$A M(\mathrm{n}=81)$} \\
\hline & & & & A & $\mathrm{H}_{o}$ & $\mathrm{H}_{e}$ & $\mathrm{~F}_{I}$ & $\mathrm{~A}$ & $\mathrm{H}_{o}$ & $\mathrm{H}_{e}$ & $\mathrm{~F}_{I}$ & A & $\mathrm{H}_{o}$ & $\mathrm{H}_{e}$ & $\mathrm{~F}_{I}$ \\
\hline \multicolumn{16}{|l|}{ Nuclear } \\
\hline WMC1E8 & $(\mathrm{AC}) \mathrm{n}$ & $\begin{array}{l}\text { Abdel-Ghani } \\
\text { et al. (2004) }\end{array}$ & $1 \mathrm{H}$ & 2 & 0.015 & 0.271 & 0.943 & 4 & 0.343 & 0.367 & 0.066 & 3 & 0.038 & 0.406 & 0.908 \\
\hline HVM20 & $(G A) n$ & Liu et al. (1996) & $1 \mathrm{H}$ & 6 & 0.431 & 0.708 & 0.392 & 7 & 0.114 & 0.337 & 0.661 & 9 & 0 & 0.427 & 1.000 \\
\hline EBmac0403 & $\begin{array}{l}(\mathrm{AC}) \mathrm{n} \\
(\mathrm{CA}) \mathrm{k}(\mathrm{TA}) \mathrm{f}\end{array}$ & $\begin{array}{l}\text { Ramsay et al. } \\
(2000)\end{array}$ & $2 \mathrm{H}$ & 6 & 0 & 0.551 & 1.000 & 9 & 0.771 & 0.712 & -0.084 & 8 & 0.038 & 0.367 & 0.898 \\
\hline Bmac0030 & $(\mathrm{AC}) \mathrm{n}$ & $\begin{array}{l}\text { Ramsay et al. } \\
(2000)\end{array}$ & $4 \mathrm{H}$ & 11 & 0 & 0.837 & 1.000 & 9 & 0.043 & 0.693 & 0.938 & 11 & 0 & 0.776 & 1.000 \\
\hline HvOle & $(\mathrm{GCCT}) \mathrm{n}$ & $\begin{array}{l}\text { Ramsay et al. } \\
(2000)\end{array}$ & $4 \mathrm{H}$ & 4 & 0 & 0.200 & 1.000 & 10 & 0.100 & 0.385 & 0.741 & 2 & 0 & 0.420 & 1.000 \\
\hline Bmac0113 & $(\mathrm{AT}) \mathrm{n}(\mathrm{AC}) \mathrm{k}$ & $\begin{array}{l}\text { Ramsay et al. } \\
(2000)\end{array}$ & $5 \mathrm{H}$ & 11 & 0 & 0.840 & 1.000 & 15 & 0.829 & 0.811 & -0.021 & 15 & 0 & 0.904 & 1.000 \\
\hline Bmag0222 & $(\mathrm{AC}) \mathrm{n}(\mathrm{AG}) \mathrm{k}$ & $\begin{array}{l}\text { Ramsay et al. } \\
(2000)\end{array}$ & $5 \mathrm{H}$ & 7 & 0 & 0.774 & 1.000 & 8 & 0 & 0.744 & 1.000 & 5 & 0 & 0.663 & 1.000 \\
\hline EBmac0824 & (TG)n(GT)k & $\begin{array}{l}\text { Ramsay et al. } \\
(2000)\end{array}$ & $5 \mathrm{H}$ & 13 & 0 & 0.905 & 1.000 & 5 & 0 & 0.666 & 1.000 & 7 & 0 & 0.698 & 1.000 \\
\hline Bmac0316 & $(\mathrm{AC}) \mathrm{n}$ & $\begin{array}{l}\text { Ramsay et al. } \\
(2000)\end{array}$ & $6 \mathrm{H}$ & 14 & 0.338 & 0.874 & 0.613 & 16 & 0.171 & 0.849 & 0.798 & 12 & 0 & 0.771 & 1.000 \\
\hline Bmac0218 & $(\mathrm{AC}) \mathrm{n}$ & $\begin{array}{l}\text { Ramsay et al. } \\
(2000)\end{array}$ & $6 \mathrm{H}$ & 6 & 0 & 0.771 & 1.000 & 11 & 0.143 & 0.853 & 0.833 & 15 & 0 & 0.773 & 1.000 \\
\hline $\begin{array}{l}\text { Locus } \\
\text { mean (s.e.) }\end{array}$ & & & & $\begin{array}{c}8.0 \\
(0.44)\end{array}$ & $\begin{array}{c}0.078 \\
(0.018)\end{array}$ & $\begin{array}{c}0.673 \\
(0.028)\end{array}$ & $\begin{array}{c}0.895 \\
(0.024)\end{array}$ & $\begin{array}{c}9.4 \\
(0.43)\end{array}$ & $\begin{array}{c}0.251 \\
(0.034)\end{array}$ & $\begin{array}{c}0.642 \\
(0.022)\end{array}$ & $\begin{array}{c}0.593 \\
(0.048)\end{array}$ & $\begin{array}{c}8.7 \\
(0.51)\end{array}$ & $\begin{array}{c}0.008 \\
(0.002)\end{array}$ & $\begin{array}{c}0.621 \\
(0.022)\end{array}$ & $\begin{array}{c}0.981 \\
(0.005)\end{array}$ \\
\hline \multicolumn{16}{|l|}{ Chloroplast } \\
\hline LF & (C)n & $\begin{array}{l}\text { Molina-Cano } \\
\text { et al. }(2005)\end{array}$ & & 2 & & 0.116 & & 1 & & 0 & & 1 & & 0 & \\
\hline S1 & (A)nCGC(T)k & $\begin{array}{l}\text { Molina-Cano } \\
\text { et al. }(2005)\end{array}$ & & 4 & & 0.348 & & 3 & & 0.109 & & 4 & & 0.487 & \\
\hline S2 & $(\mathrm{T}) \mathrm{n}$ & $\begin{array}{l}\text { Molina-Cano } \\
\text { et al. }(2005)\end{array}$ & & 1 & & 0 & & 3 & & 0.207 & & 3 & & 0.163 & \\
\hline $\mathrm{sbA}$ & $(\mathrm{T}) \mathrm{n}$ & $\begin{array}{l}\text { Molina-Cano } \\
\text { et al. (2005) }\end{array}$ & & 2 & & 0.355 & & 3 & & 0.540 & & 3 & & 0.417 & \\
\hline sbK & (A)n & $\begin{array}{l}\text { Molina-Cano } \\
\text { et al. }(2005)\end{array}$ & & 2 & & 0.260 & & 2 & & 0.265 & & 2 & & 0.305 & \\
\hline $\begin{array}{l}\text { Locus } \\
\text { mean (s.e.) }\end{array}$ & & & & $\begin{array}{c}2.2 \\
(0.27)\end{array}$ & & $\begin{array}{c}0.216 \\
(0.039)\end{array}$ & & $\begin{array}{c}2.4 \\
(0.22)\end{array}$ & & $\begin{array}{c}0.224 \\
(0.051)\end{array}$ & & $\begin{array}{c}2.6 \\
(0.28)\end{array}$ & & $\begin{array}{c}0.274 \\
(0.049)\end{array}$ & \\
\hline
\end{tabular}

Abbreviations: $A$, number of alleles; $H_{\mathrm{e}}$, expected heterozygosity; $H_{\mathrm{o}}$, observed heterozygosity; $F_{\mathrm{I}}$, inbreeding coefficient.

Mean values are provided with s.e. obtained by jackknifing over loci (in parentheses).

Table 2 Spatial genetic structure and estimates of gene dispersal

\begin{tabular}{|c|c|c|c|c|c|c|}
\hline Population & Distance range $(m)$ & $\mathrm{b}$ (s.e.) & P-value & $\mathrm{F}_{(1)}$ & Sp & $\mathrm{Nb}(95 \% C I)$ \\
\hline SB & $0-400$ & $-0.0410(0.0161)$ & 0.0136 & 0.3761 & 0.0657 & $15.2(8.5-70.9)$ \\
\hline SB & $0-20$ & $-0.1119(0.0316)$ & 0.0011 & 0.3761 & 0.1793 & $5.6(3.6-12.8)$ \\
\hline BG & $0-400$ & $-0.0446(0.0133)$ & 0.0014 & 0.2317 & 0.0580 & $17.2(10.8-42.7)$ \\
\hline BG & $0-20$ & $-0.0555(0.0255)$ & 0.0356 & 0.2317 & 0.0722 & $13.8(7.2-170.7)$ \\
\hline $\mathrm{AM}$ & $0-400$ & $-0.0517(0.0113)$ & $<0.0001$ & 0.4177 & 0.0888 & $11.3(7.8-20.0)$ \\
\hline $\mathrm{AM}$ & $0-20$ & $-0.1041(0.0279)$ & 0.0006 & 0.4177 & 0.1788 & $5.6(3.6-12.0)$ \\
\hline
\end{tabular}

Abbreviations: AM, Mediterranean grassland; $b$, the regression slope of multilocus kinship coefficients for pairs of individuals against the logarithm of geographic distance separating members of the pair; BG, batha; $\mathrm{CI}$, confidence interval; $F_{(1)}$, kinship coefficient between adjacent (1 m apart) individuals; $N b$, neighborhood size; $P$, level of significance; $\mathrm{SB}$, desert; $S p=(1 / \mathrm{Nb})$, a measure of the extent of SGS.

To calculate the ratio of pollen flow to seed flow, we used the formula from Ennos (1994), pollen flow/seed flow $=\left[\left(1 / \phi_{\mathrm{SN}}-1\right)-2\left(1 / \phi_{\mathrm{SC}}-1\right)\right] /\left(1 / \phi_{\mathrm{SC}}-1\right)$, where $\phi_{\mathrm{SN}}$ and $\phi_{\mathrm{SC}}$ are levels of subpopulation differentiation calculated from nuclear and chloroplast markers, respectively. Analysis of molecular variance (Excoffier et al., 1992) was used to get the $\phi_{\mathrm{SN}}$ and $\phi_{\mathrm{SC}}$ values for each population separately. In each population, $\phi_{\mathrm{SN}}$ and $\phi_{\mathrm{SC}}$ were estimated for subpopulations (that is, parts of the transect from the starting plant) of increasing size (from 1 to $50 \mathrm{~m}$ ).

\section{Results}

\section{Seed dispersal experiment}

In the seed dispersal experiment, no seed was found beyond $2 \mathrm{~m}$ distance from the mother plant. The 


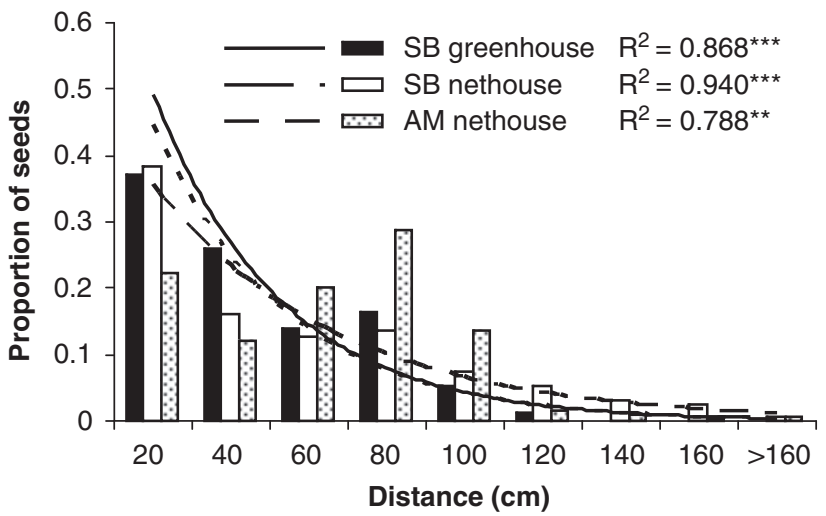

Figure 2 Seed dispersal in wild barley measured as distance from the mother plant.

histograms and approximated dispersal curves for seeds of the three plants (Figure 2) indicate that major seed dispersal ( $\geqslant 95 \%)$ in wild barley is within $1.2 \mathrm{~m}$ of the seed plant with a negligible fraction dispersing above $1.6 \mathrm{~m}(\leqslant 1 \%)$. This pattern of dispersal was not affected by seed weight or whether the plants were grown in a greenhouse or a nethouse $(32.0 \pm 0.1,32.3 \pm 0.1$ and $74.0 \pm 0.3 \mathrm{mg}$ seed weights for SB plants grown in a greenhouse and a nethouse, and the AM plant grown in a nethouse, respectively). On the other hand, spatial distribution of shattered seeds of the same genotype was more leptokurtic and had a longer tail in the nethouse than in the greenhouse (Kolmogorov-Smirnov test, maximum difference of $0.126, P<0.001)$. The difference between nethouse and greenhouse was due to wind, present in the former and absent in the latter, although the wind effect may have reduced by the net mesh. Thus, wind did influence the shape of the seed dispersal curve, but the effect is very limited (maximum dispersal distance from the mother plant was $<2 \mathrm{~m}$, Figure 2).

\section{Genetic diversity within populations}

Genetic diversity statistics for the three populations are given in Table 1. Average number of alleles per locus, $A$, and expected heterozygosity, $H_{\mathrm{e}}$, were similar in all populations, with a range of 8.0-9.4 and 0.621-0.673, respectively. However, observed heterozygosity, $H_{0}$, and inbreeding coefficient, $F_{\mathrm{I}}$, did differ among populations: $\mathrm{AM}$ and $\mathrm{SB}$ had low proportions of heterozygotes $\left(H_{\mathrm{o}}=0.008, F_{\mathrm{I}}=0.981\right.$ and $H_{\mathrm{o}}=0.078, F_{\mathrm{I}}=0.895$, respectively), whereas the proportion of heterozygotes in BG was much higher $\left(H_{\mathrm{o}}=0.251, F_{\mathrm{I}}=0.593\right)$.

\section{SGS}

We found significant autocorrelations for the first two distance classes ( 1 and $2 \mathrm{~m}$ ) in two populations (SB and $\mathrm{AM})$, and for the first distance class $(1 \mathrm{~m})$ in the BG population (Figure 3).

There was a significant linear decrease in estimated kinship coefficients between pairs of individuals with the logarithm of increasing geographical distance in all three populations (Figure 4). Variance explained by the regression $\left(r^{2}\right)$ ranged from 0.101 to 0.264 . The pattern was similar for both distance ranges (1-400 and 1-20 m); however, regression slopes were steeper for the distance range of $1-20 \mathrm{~m}$ than for $1-400 \mathrm{~m}$ in $\mathrm{SB}$ and $\mathrm{AM}$

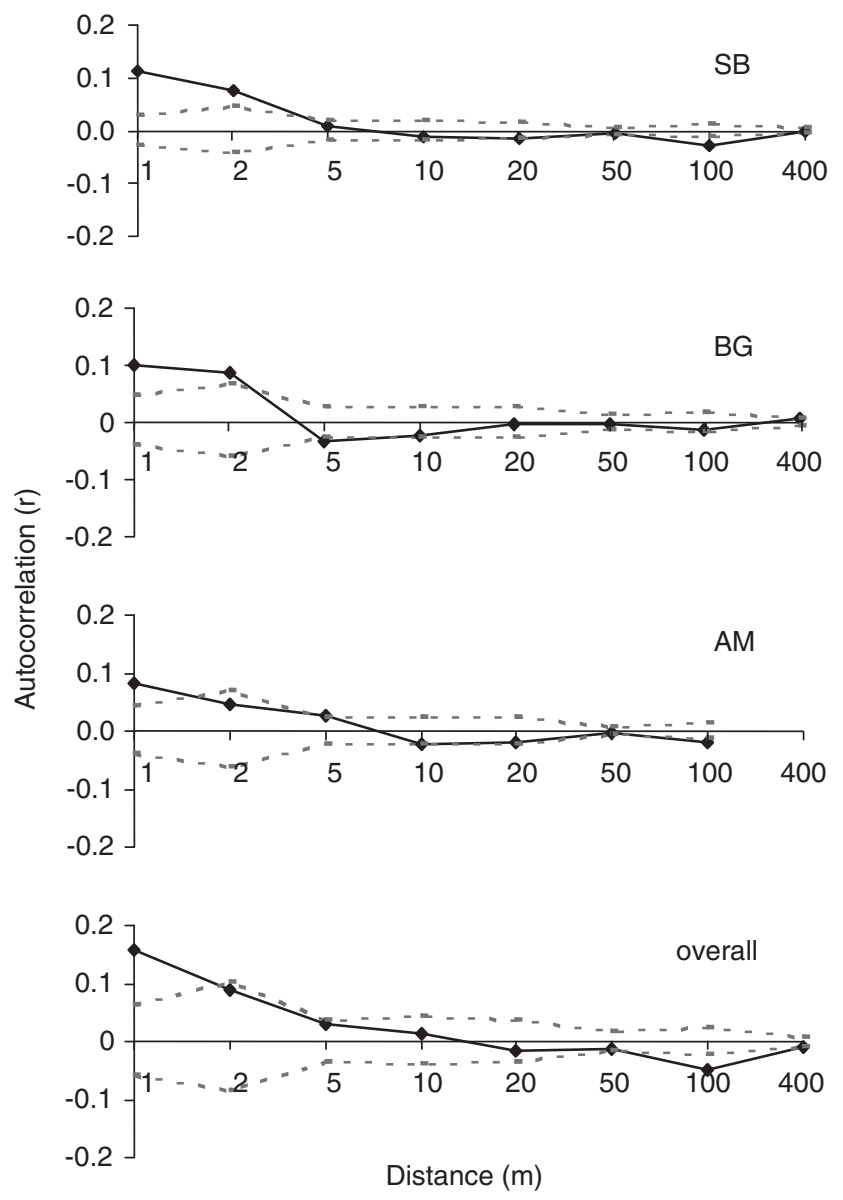

Figure 3 Autocorrelograms with 95\% confidence intervals (dotted lines) for autocorrelation coefficient $r$ (solid line) calculated for the three populations individually and overall.

populations ( $t=2.0$ and 1.8, $P<0.05$, one-sided $t$-test) but not in the BG population $(t=0.4, P>0.05, t$-test $)$ (Table 2). A comparison of population-specific regression slopes for the distance range $1-20 \mathrm{~m}$, revealed no difference between $\mathrm{AM}$ and $\mathrm{SB}$ populations $(t=0.2$, $P>0.05, t$-test), but a steeper slope for BG compared with either AM or SB $(t=1.3$ and $1.4, P<0.10$, one-sided $t$-test $)$.

Neighborhood size, $\mathrm{Nb}$, was estimated for each population based on regression slopes obtained for two distance ranges, 1-400 and 1-20 m (Table 2). Despite a difference between distance ranges and population average kinship coefficients for the most spatially close plants ( $1 \mathrm{~m}$ apart), the population $\mathrm{Nb}$ estimates were within a quite narrow range of 5.6-17.2. The $N b$ values estimated for 1-20 m distance range were smaller than for $1-400 \mathrm{~m}$ in the SB and AM populations, but confidence limits of the two $\mathrm{Nb}$ values overlapped (Table 2).

$S p$ values obtained for the two distance ranges, 1-400 and $1-20 \mathrm{~m}$, ranged from 0.058 to 0.179 . The average kinship coefficients between adjacent $(1 \mathrm{~m}$ apart) individuals, $F_{(1)}$, were estimated as $0.38,0.23$ and 0.42 , and the population inbreeding coefficients, $F_{\mathrm{I}}$, as $0.89,0.59$ and 0.98 for SB, BG and AM populations, respectively.

Plant densities in the SB and BG populations ranged from 22.2 to 38.9 and from 29.2 to 194.9 plants per $1 \mathrm{~m}^{2}$, respectively (Table 3 ). The inferred standard deviation of 

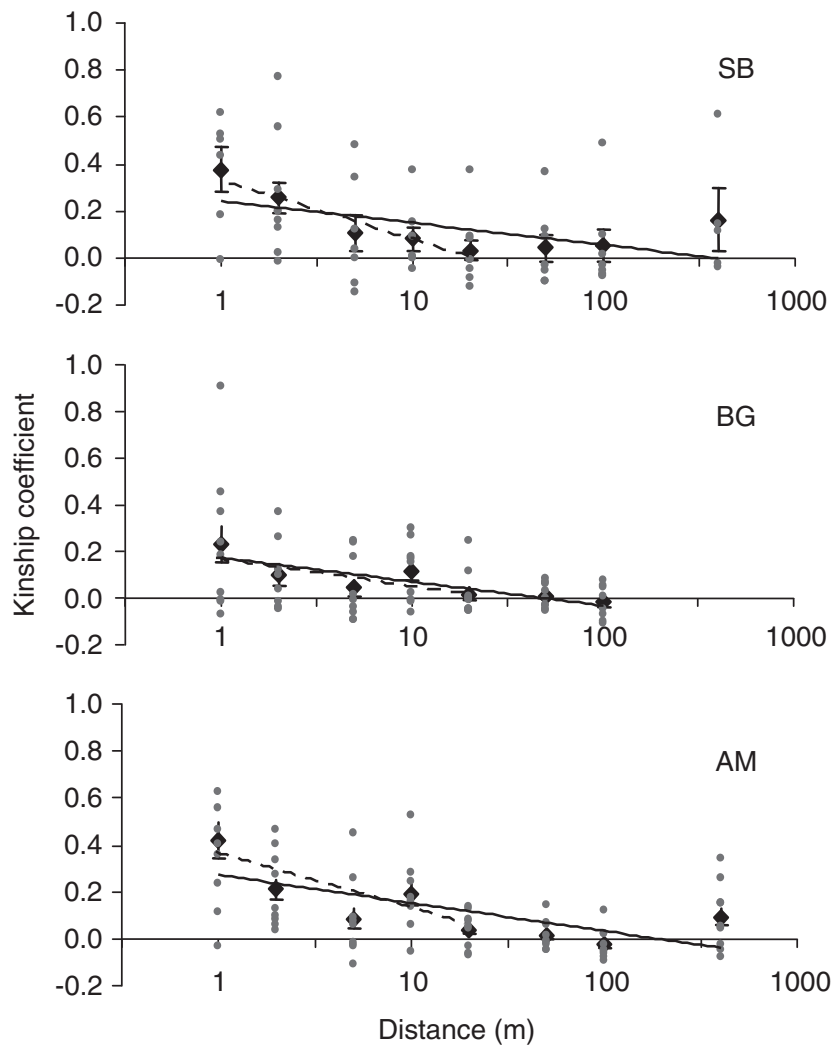

Figure 4 Ritland's kinship coefficients for pairs of individuals plotted against the logarithm of geographic distance separating members of the pairs, the estimated regression lines and the average multilocus kinship coefficients \pm 2 s.e. for each distance class. The regression lines were obtained for the distance ranges, $1-400 \mathrm{~m}$ (solid line) and 1-20 m (dashed line).

gene dispersal $(\sigma)$ calculated from year-specific population densities and $S p$ values obtained for distance ranges of $0-400$ and $0-20 \mathrm{~m}$ are given in Table 3 . Very low values of $\sigma$ were observed in both populations in all years of observations (range $0.11-0.74$ ), despite a high variation in plant density.

\section{Pollen to seed flow}

Genetic diversity estimated from chloroplast markers was similar in the three populations (Table 1). Pollen flow did not differ from seed dispersal as estimated for subpopulations of sizes ranging $1-50 \mathrm{~m}$ in the $\mathrm{AM}$ population (Table 4). In the other two populations, the ratio of pollen flow to seed flow $m_{\mathrm{p}} / m_{\mathrm{s}}$ increased with the increase in subpopulation size (Table 4), although the increase did not seem to be linear (Figure 5). The increase was especially pronounced in the BG population (from 6 to 30$)$.

\section{Discussion}

\section{SGS in a predominant selfer}

In most plant species, seed dispersal has a unimodal leptokurtic distribution with a peak at or close to the mother plant and a long tail of progressively fewer seeds with increasing distance from the plant (Levin and Kerster, 1974; Portnoy and Willson, 1993; Willson, 1993; Schupp and Fuentes, 1995). We estimated an appro- ximate seed dispersal curve for H. spontaneum. Under our experimental conditions (artificial growing conditions, exclusion of all the biotic seed dispersers such as rodents, ants and birds), most seed dispersal was within about $1 \mathrm{~m}$ of the seed parent. The effect of wind on the shape of the dispersal curve was moderate (Figure 2), but our experiment had limitations in estimating the effect of wind because we experienced no strong winds during the period of seed shed. Strong winds may be rare events that do not happen every year and in all locations where $H$. spontaneum occurs, thus the actual effect of wind on seed dispersal in wild barley may be stronger than observed in our experiment.

The expected heterozygosity was similar across all three populations, suggesting a similar within-population genetic variation. The AM and SB populations had low numbers of heterozygotes, consistent with the low level of outcrossing reported in the literature (Brown et al., 1978b; Volis et al., 2001a). However, the BG population had many heterozygotes. From other population studies done on wild barley with SSRs (Abdel-Ghani et al., 2004), we may quite surely state that this is an atypical situation. Nevertheless, the SGS pattern in this population did not differ from the other two.

The SGS pattern detected in all three populations by both spatial autocorrelation analysis and regressing relatedness coefficients on distance was consistent with IBD. The values for the regression slopes, for neighborhood size $\mathrm{Nb}$ and for the $\mathrm{Sp}$ statistic, all indicated higher SGS at the scale of $20 \mathrm{~m}$ as compared with $400 \mathrm{~m}$. These values were consistent in populations separated by more than $100 \mathrm{~km}$ and having different environmental conditions and population history, which suggests that common processes operate across the species range. The $S p$ values obtained in this study were similar to those reported for other predominant selfers (Vekemans and Hardy, 2004), although the plant densities in wild barley populations were the highest among the studied self-pollinated species (Vekemans and Hardy, 2004).

Put together, our findings present an interesting phenomenon. On the one hand, the species has very limited seed dispersal, a clear IBD and a very fine SGS. On the other, plant density is high (from 20 to 200 adult plants $/ \mathrm{m}^{2}$ ), which should strongly reduce the effect of genetic drift. The $S p$ statistic is expected to be inversely related to the plant density under IBD (Heywood, 1991; Vekemans and Hardy, 2004). This statistic, proposed as a universal measure of the extent of SGS in different populations and species, indicates strong SGS in wild barley despite high plant density. This implies that in predominant selfers with localized seed dispersal, gene flow is low even under high plant density. However, the gene flow is not zero and is sufficient to create an isolation-by-distance pattern. Thus, selfing, localized seed dispersal and high plant density act together to create an equilibrium between drift and gene flow, which results in SGS at a very fine spatial scale. In this regard, an interesting question is: what is a role of occasional outcrossing (that is, pollen dispersal) on SGS?

For self-incompatable or highly outcrossing species, within-population gene flow is mainly through pollen, and gene flow among populations is through both pollen and seeds. In predominant selfers, the importance of pollen flow in general is much lower than in outcrossing species, both within and among populations. However, if 
Table 3 Effect of population plant density and sampling distance on inferred gene dispersal

\begin{tabular}{lcccccc}
\hline Population & Year & $\mathrm{D}($ s.e. $)$ & $\sigma_{(20)}(\mathrm{m})\left(\mathrm{D}_{e}=\mathrm{D} / 2\right)$ & $\sigma_{(20)}(\mathrm{m})\left(\mathrm{D}_{e}=D / 10\right)$ & $\sigma_{(400)}(\mathrm{m})\left(\mathrm{D}_{e}=\mathrm{D} / 2\right)$ & $\sigma_{(400)}(\mathrm{m})\left(\mathrm{D}_{e}=\mathrm{D} / 10\right)$ \\
\hline SB & 1996 & $22.2(6.7)$ & $0.20(0.16-0.30)$ & $0.45(0.36-0.68)$ & $0.33(0.24-0.71)$ & $0.74(0.55-1.59)$ \\
& 1997 & $38.9(11.0)$ & $0.15(0.12-0.23)$ & $0.34(0.27-0.51)$ & $0.25(0.19-0.54)$ & $0.56(0.42-1.20)$ \\
& 1998 & $30.6(10.9)$ & $0.17(0.14-0.26)$ & $0.38(0.30-0.58)$ & $0.28(0.21-0.61)$ & $0.63(0.47-1.36)$ \\
BG & & & & & & \\
& 1996 & $40.0(5.7)$ & $0.23(0.17-0.82)$ & $0.52(0.38-1.84)$ & $0.26(0.21-0.41)$ & $0.59(0.46-0.92)$ \\
& 1997 & $84.3(17.6)$ & $0.16(0.12-0.57)$ & $0.36(0.26-1.27)$ & $0.18(0.14-0.28)$ & $0.40(0.32-0.63)$ \\
& 1998 & $194.9(27.5)$ & $0.11(0.08-0.37)$ & $0.24(0.17-0.83)$ & $0.12(0.09-0.19)$ & $0.27(0.21-0.42)$ \\
& 1999 & $29.2(4.3)$ & $0.27(0.20-0.96)$ & $0.61(0.44-2.16)$ & $0.31(0.24-0.48)$ & $0.69(0.54-1.08)$ \\
\hline
\end{tabular}

Abbreviations: BG, batha; SB, desert.

Gene dispersal distances $(\sigma)$ followed by $95 \%$ confidence intervals are calculated from data sampled over 20 and $400 \mathrm{~m}$ for two effective densities $\left(D_{\mathrm{e}}\right)$ estimated from the density of adults $(D)$.

Table 4 Partitioning of nuclear $\left(\phi_{\mathrm{SN}}\right)$ and chloroplast $\left(\phi_{\mathrm{SC}}\right)$ variation among subpopulations of different diameter, and ratios of pollen to seed dispersal $\left(m_{\mathrm{p}} / m_{\mathrm{s}}\right)$ in the three populations

\begin{tabular}{|c|c|c|c|c|c|c|c|c|c|}
\hline \multirow[t]{3}{*}{ Subpopulation diameter $(\mathrm{m})$} & \multicolumn{9}{|c|}{ Population } \\
\hline & \multicolumn{3}{|c|}{$S B$} & \multicolumn{3}{|c|}{$B G$} & \multicolumn{3}{|c|}{$A M$} \\
\hline & $\phi_{S N}$ & $\phi_{S C}$ & $\mathrm{~m}_{p} / \mathrm{m}_{s}$ & $\phi_{S N}$ & $\phi_{S C}$ & $\mathrm{~m}_{p} / \mathrm{m}_{s}$ & $\phi_{S N}$ & $\phi_{S C}$ & $\mathrm{~m}_{p} / \mathrm{m}_{s}$ \\
\hline 1 & 0.246 & 0.153 & -1.446 & 0.116 & 0.540 & 6.946 & 0.357 & 0.432 & -0.630 \\
\hline 2 & 0.202 & 0.371 & 0.330 & 0.130 & 0.558 & 6.449 & 0.309 & 0.472 & -0.001 \\
\hline 5 & 0.131 & 0.360 & 1.731 & 0.093 & 0.604 & 12.875 & 0.260 & 0.389 & -0.188 \\
\hline 10 & 0.051 & 0.336 & 7.416 & 0.068 & 0.626 & 20.941 & 0.234 & 0.350 & -0.237 \\
\hline 20 & 0.087 & 0.396 & 4.880 & 0.066 & 0.614 & 20.510 & 0.204 & 0.331 & -0.069 \\
\hline 50 & 0.082 & 0.333 & 3.514 & 0.050 & 0.629 & 30.213 & 0.177 & 0.334 & 0.332 \\
\hline
\end{tabular}

Abbreviations: AM, Mediterranean grassland; BG, batha; SB, desert.
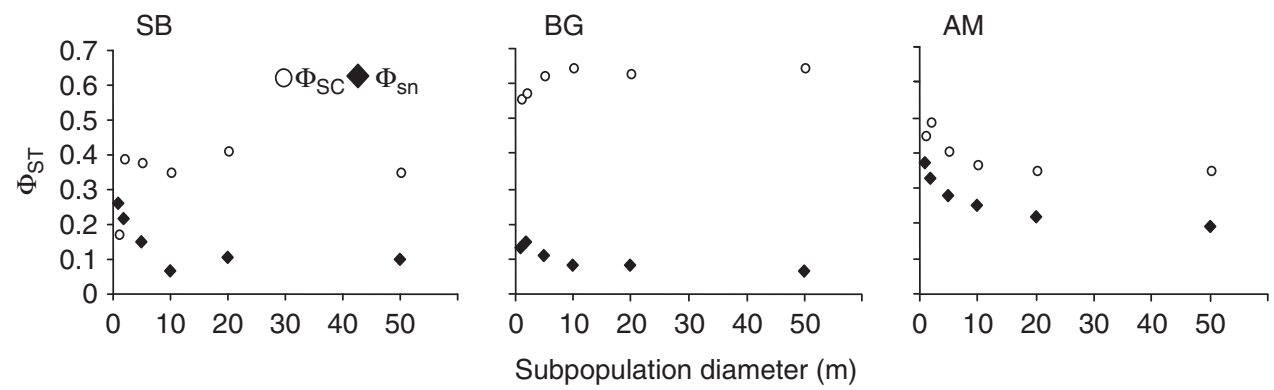

Figure 5 Nuclear and chloroplast $\phi_{\mathrm{ST}}\left(\phi_{\mathrm{SN}}\right.$ and $\phi_{\mathrm{SC}}$, respectively) values estimated for subpopulations of different size in the three populations.

frequency of outcrossing increases due to high density and frequent strong winds (apparently, a situation in the BG population where plant density in favorable years can reach several hundred plants per square meter), the resulting $m_{\mathrm{p}} / m_{\mathrm{s}}$ becomes similar to that observed in outcrossing species. In the BG population, higher outcrossing is evident in the higher observed heterozygosity ( 0.251 vs 0.078 and 0.008 in the other two populations). The higher outcrossing in the BG population can be either an exception with this population or, alternatively, typical but ephemeral for any population as a consequence of rare or sporadically occurring environmental conditions (temperature, humidity, wind, etc.). Several of our findings support the second explanation. The SGS in the BG population did not differ from the SGS in the other two populations, as is evident from the same scale of autocorrelation and similar IBD slopes for the whole distance range of $1-400 \mathrm{~m}$. At the same time, the IBD slope for the distance range 1-20 $\mathrm{m}$ was shallower for BG as compared with both SB and AM populations. The latter appears to be a transient effect of one or a few events of cross-pollination in this population.

Altogether our results indicate that in predominant selfers, pollen flow, despite lower importance as compared with outcrossers, may contribute to the SGS by rare outcrossing events followed by many generations of selfing. If the outcross genotypes established and became locally abundant after segregation, as implied by the results of crossbreeding experiments (Volis et al., unpublished results), they would create a very fine scale, but distinct SGS. Epperson (2007) showed in a simulation study that when seed dispersal is highly limited, SGS is larger under moderate selfing rate than under high selfing rate.

It should be noted, that this study quantified SGS for seed dispersal (that is, where do seeds fall) but not the 
effective dispersal (that is, where do plants arise in space). Biological processes might cause the spatial distribution of adult plant genotypes to differ from the spatial distribution of dispersed seed, and these processes are not accounted for. For example, natural selection may affect SGS through creation of a spatial mosaic of various locally abundant genotypes adapted to either the same environmental problem ('adaptive peaks') or to multiple biotic/abiotic problems on a very fine spatial scale (local microadaptations) (Volis et al., unpublished results). For example, frequency of the established heterozygous genotypes and of their progeny segregating under self-pollination could be lower than their frequency at the stage of seed dispersal, as suggested by the crossbreeding experiment (Volis et al., unpublished results).

\section{Pollen to seed flow in a predominant selfer}

Our study is the first to characterize SGS and quantify pollen to seed flow in a predominantly selfing species at a fine spatial scale. Major seed dispersal was by gravity, with minor additional impact of wind. The quantitative effect of animal dispersal is unknown, but occasional long distance dispersal occurs when spikelets get entrapped in animals' fur.

The species is a predominant selfer $(>98 \%)$ with a relatively short pollen life of up to $26 \mathrm{~h}$ (Parzies et al., 2005). The bulk of the outcrossing occurs between adjacent plants, but hybrids were detected up to a distance of $60 \mathrm{~m}$ indicating rare longer distance migration (Wagner and Allard, 1991). Our data suggested that under certain, currently unknown, circumstances, pollen flow may become substantial as evidenced by high observed heterozygosity in the BG population. Other studies have indicated that high annual precipitation and cool temperature during flowering time may enhance outcrossing in wild barley (Brown et al., 1978b; Abdel-Ghani et al., 2004).

In several outcrossing herbs, mean pollen dispersal distance ranged from 5 to $15 \mathrm{~m}$ (Meagher and Thompson, 1987; Godt and Hamrick, 1993; Miyazaki and Isagi, 2000; Tero et al., 2005). No comparable data exist for predominantly selfing species.

The ratio of pollen-to-seed flow has been analyzed in several outcrossing herbs, and was much higher than unity (McCauley, 1997, 1998; Tarayre et al., 1997). A comparison with predominant selfers is limited to H. spontaneum (Ennos, 1994). A pollen/seed flow ratio for this species was calculated from the data of Nevo et al. (1979) and Neale et al. (1988) ( $\phi_{\mathrm{SN}}$ of 0.49 and $\phi_{\mathrm{SC}}$ of 0.735 , providing $\left.m_{\mathrm{p}} / m_{\mathrm{s}}=4\right)$ (Ennos, 1994), but this ratio should be treated with caution because of the large spatial scale (tens and hundreds of kilometers). In our study, the pollen/seed migration ratio, $m_{\mathrm{p}} / m_{\mathrm{s}}$, derived from the comparison of chloroplast and nuclear $\phi_{\mathrm{ST}}$, depended strongly on delineation of subpopulations. In all three populations, the ratio increased with increasing subpopulation spatial scale (Table 4). The fine scale of SGS in this species appears to be the cause of the increase. As the SGS was about $2 \mathrm{~m}$, subpopulations of larger size would comprise several genetically differentiated neighborhoods. We conclude that the underestimation of true population subdivision results in overestimating the importance of pollen flow.
The importance of spatial scale for sampling of pollento-seed flow ratio was also shown by McCauley (1997). In his study of the dioecious insect-pollinated herb Silene alba, pollen-to-seed flow ratios were 3.4, 9.2 and 124.0 for scales of kilometers, tens of meters and meters. A similar pattern was described for a gynodioecious perennial Thymus vulgaris (pollen to seed flow ratios were 59.4 and 13.5 for small and large scale, respectively) (Tarayre et al., 1997). However, an increase in pollen-to-seed flow ratio with distance from 50 to $500 \mathrm{~km}$ was shown for the tree Sorbus torminalis (Oddou-Muratorio et al., 2001). These results show that the contribution of seed and pollen flow to SGS changes with spatial scale, and may critically depend on plant life history. It was repeatedly noted (Hardy and Vekemans, 1999; Vekemans and Hardy, 2004; Epperson, 2005) that inferences about SGS are more robust to differences in population age if based on short distance classes. This is because processes that affect demographic structure (for example, local extinction) will have higher inflating effect on estimates of SGS made for larger distance classes than for smaller distance classes. These processes should be especially important for short-lived plants, first of all annuals, because of their high turnover rate.

\section{Conclusions}

We analyzed SGS in a predominantly selfing plant with a localized seed dispersal. We found that gene flow in $H$. spontaneum is low, even under high plant density, but still sufficient for the creation of an IBD pattern. Combined effects of selfing, occasional outcrossing, localized seed dispersal and high plant density create equilibrium between drift and gene flow, resulting in SGS at a very fine spatial scale. Pollen flow through occasional outcrossing appears to be as spatially limited as seed dispersal in this species. Pollen to seed flow tends to be overestimated when measured at spatial scales exceeding that of SGS. From this we conclude that without prior knowledge of SGS, the derived $m_{\mathrm{p}} / m_{\mathrm{s}}$ ratio has a high chance of being incorrect. The conclusion applies primarily to the studies on within-population genetic variation and when plant distribution is continuous or not distinctly clumped.

\section{Conflict of interest}

The authors declare no conflict of interest.

\section{Acknowledgements}

We would like to thank Gil Bohrer, Richard Nichols, Christian Parisod, Frank Sorensen, Koen Verhoeven and four anonymous reviewers for helpful comments on an early version of the paper.

\section{References}

Abdel-Ghani AH, Parzies HK, Omary A, Geiger HH (2004). Estimating the outcrossing rate of barley landraces and wild barley populations collected from ecologically different regions of Jordan. Theor Appl Genet 109: 588-595.

Brown AHD, Nevo E, Zohary D, Dagan O (1978a). Genetic variation in natural populations of wild barley (Hordeum spontaneum). Genetica 49: 97-108. 
Brown AHD, Zohary D, Nevo E (1978b). Outcrossing rates and heterozygosity in natural populations of Hordeum spontaneum Koch in Israel. Heredity 41: 49-62.

Cavers S, Degen B, Caron H, Lemes MR, Margis R, Salgueiro F et al. (2005). Optimal sampling strategy for estimation of spatial genetic structure in tree populations. Heredity 95: 281-289.

El Mousadik A, Petit RJ (1996). Chloroplast DNA phylogeography of the argan tree of Morocco. Mol Ecol 5: 547-555.

Ennos RA (1994). Estimating the relative rates of pollen and seed migration among plant populations. Heredity 72: 250-259.

Epperson BK (2005). Estimating dispersal from short distance spatial autocorrelation. Heredity 95: 7-15.

Epperson BK (2007). Plant dispersal, neighbourhood size and isolation by distance. Mol Ecol 16: 3854-3865.

Epperson BK, Li TQ (1996). Measurement of genetic structure within populations using Moran's spatial autocorrelation statistics. Proc Natl Acad Sci USA 93: 10528-10532.

Epperson BK, Li TQ (1997). Gene dispersal and spatial genetic structure. Evolution 51: 672-681.

Excoffier L, Smouse PE, Quattro JM (1992). Analysis of molecular variance inferred from metric distances among DNA haplotypes-application to human mitochondrial DNA restriction data. Genetics 131: 479-491.

Frankham R (1995). Effective population size/adult population size ratios in wildlife-a review. Genet Res 66: 95-107.

Godt MJW, Hamrick JL (1993). Patterns and levels of pollenmediated gene flow in Lathyrys latifolius. Evolution 47: 98-110.

Gutterman Y (1992). Ecophysiology of Negev upland annual grasses. In: Chapman GP (ed). Desertified Grassland: Their Biology and Management (Linnean Society Symposium Series 13). Academic Press: London. pp 145-162.

Hamilton MB, Miller JR (2002). Comparing relative rates of pollen and seed gene flow in the island model using nuclear and organelle measures of population structure. Genetics 162: 1897-1909.

Hardy OJ (2003). Estimation of pairwise relatedness between individuals and characterization of isolation-by-distance processes using dominant genetic markers. Mol Ecol 12: $1577-1588$.

Hardy OJ, Maggia L, Bandou E, Breyne P, Caron H, Chevallier $\mathrm{MH}$ et al. (2006). Fine-scale genetic structure and gene dispersal inferences in 10 Neotropical tree species. Mol Ecol 15: 559-571.

Hardy OJ, Vekemans X (1999). Isolation by distance in a continuous population: reconciliation between spatial autocorrelation analysis and population genetics models. Heredity 83: 145-154.

Harlan RJ, Zohary D (1966). Distribution of wild wheats and barley. Science 153: 1074-1080.

Heuertz M, Vekemans X, Hausman JF, Palada M, Hardy OJ (2003). Estimating seed vs pollen dispersal from spatial genetic structure in the common ash. Mol Ecol 12: 2483-2495.

Heywood JS (1991). Spatial analysis of genetic variation in plant populations. Annu Rev Ecol Syst 22: 335-355.

Leblois R, Estoup A, Rousset F (2003). Influence of mutational and sampling factors on the estimation of demographic parameters in a 'continuous' population under isolation by distance. Mol Biol Evol 20: 491-502.

Levin DA, Kerster HW (1974). Gene flow in seed plants. Evol Biol 7: 139-220.

Liu Z-W, Biyashev RM, Saghai Maroof MA (1996). Development of simple sequence repeat DNA markers and their integration into a barley linkage map. Theor Appl Genet 93: 869-876.

McCauley DE (1997). The relative contributions of seed and pollen movement to the local genetic structure of Silene alba. J Hered 88: 257-263.

McCauley DE (1998). The genetic structure of a gynodioecious plant: nuclear and cytoplasmic genes. Evolution 52: 255-280.
Meagher TR, Thompson E (1987). Analysis of parentage for naturally established seedlings of Chamaelerium luteum (Liliacae). Ecology 68: 803-812.

Miyazaki Y, Isagi Y (2000). Pollen flow and the interpopulation genetic structure of Helioniopsis orientalis on the forest floor as determined using microsatellite markers. Theor Appl Genet 101: 718-723.

Molina-Cano J-L, Russell JR, Moralejo MA, Escacena JL, Arias G, Powell W (2005). Chloroplast DNA microsatellite analysis supports a polyphyletic origin for barley. Theor Appl Genet 110: $613-619$.

Morrell PL, Lundy KE, Clegg MT (2003). Distinct geographic patterns of genetic diversity are maintained in wild barley (Hordeum vulgare ssp. spontaneum) despite migration. Proc Natl Acad Sci USA 100: 10812-10817.

Neale DB, Saghai-Maroof MA, Allard RW, Zhang Q, Jorgensen RA (1988). Chloroplast DNA diversity in populations of wild and cultivated barley. Genetics 120: 1105-1110.

Nevo E, Zohary D, Brown ADH, Haber M (1979). Genetic diversity and environmental associations of wild barley, Hordeum spontaneum in Israel. Evolution 33: 815-833.

Oddou-Muratorio S, Klein EK (2008). Comparing direct vs indirect estimates of gene flow within a population of a scattered tree species. Mol Ecol 17: 2743-2754.

Oddou-Muratorio S, Petit RJ, Le Guerroue B, Guesnet D, Demesure B (2001). Pollen- versus seed-mediated gene flow in a scattered forest tree species. Evolution 55: 1123-1135.

Ouborg NJ, Piquot Y, Van Groenendael JM (1999). Population genetics, molecular markers and the study of dispersal in plants. J Ecol 87: 551-568.

Parzies HK, Schnaithmann F, Geiger HH (2005). Pollen viability of Hordeum spp genotypes with different flowering characteristics. Euphytica 145: 229-235.

Peakall R, Ruibal M, Lindemayer DB (2003). Spatial autocorrelation analysis of individual multiallele and multilocus genetic structure. Heredity 82: 561-573.

Peakall R, Smouse PE (2006). GENALEX 6: genetic analysis in Excel. Population genetic software for teaching and research. Mol Ecol Notes 6: 288-295.

Petit RJ, Kremer A, Wagner DB (1993). Finite island model for organelle and nuclear genes. Heredity 71: 630-641.

Pollak E (1987). On the theory of partially inbreeding finate populations. I. Partial selfing. Genetics 117: 353-360.

Portnoy S, Willson MF (1993). Seed dispersal curves: behavior of the tails of the distribution. Evol Ecol 7: 25-44.

Ramsay L, Macaulay M, Degli Ivanissevich S, MacLean K, Cardle L, Fuller J et al. (2000). A simple sequence repeatbased linkage map of barley. Genetics 156: 1997-2005.

Raspe O, Saumitou-Laprade P, Cuguen J, Jacquemart AL (2000). Chloroplast DNA haplotype variation and population differentiation in Sorbus aucuparia L. (Rosaceae: Maloideae). Mol Ecol 9: 1113-1122.

Ritland K (1996). Estimators for pairwise relatedness and individual inbreeding coefficients. Genet Res 67: 175-185.

Rogers SO, Benedich AJ (1985). Extraction of DNA from milligram amounts of fresh, herbarium and mummified plant tissues. Plant Mol Biol 5: 69-76.

Rousset F (1997). Genetic differentiation and estimation of gene flow from F-statistics under isolation by distance. Genetics 145: 1219-1228.

Rousset F (2000). Genetic differentiation between individuals. I Evol Biol 13: 58-62.

Schuelke M (2000). An economic method for the fluorescent labelling of PCR fragments. Nat Biotechnol 18: 233-234.

Schupp EW, Fuentes M (1995). Spatial pattern of seed dispersal and the unification of plant population ecology. Ecoscience 2: 267-275.

Smouse PE, Peakall R (1999). Spatial autocorrelation analysis of individual multiallele and multilocus genetic structure. Heredity 82: 561-573. 
Tarayre M, Saumitou-Laprade P, Cuguen J, Couvet D, Thompson JD (1997). The spatial genetic structure of cytoplasmic (cpDNA) and nuclear (allozyme) markers within and among populations of the gynodioecious Thymus vulgaris (Labiatae) in southern France. Am J Bot 84: 1675-1684.

Tero N, Aspi J, Siikamaki P, Jakalaniemi A (2005). Local genetic population structure in an endangered plant species, Silene tatarica (Caryophyllaceae). Heredity 94: 478-487.

Turpeinen T, Tenhola T, Manninen O, Nevo E, Nissila E (2001). Microsatellite diversity associated with ecological factors in Hordeum spontaneum populations in Israel. Mol Ecol 10: 1577-1591.

Turpeinen T, Vanhala T, Nevo E, Nissila E (2003). AFLP genetic polymorphism in wild barley (Hordeum spontaneum) populations in Israel. Theor Appl Genet 106: 1333-1339.

Vekemans X, Hardy OJ (2004). New insights from fine-scale spatial genetic structure analyses in plant populations. Mol Ecol 13: 921-935.

Volis S, Mendlinger S, Turuspekov Y, Esnazarov U (2002a). Phenotypic and allozyme variation in Mediterranean and desert populations of wild barley, Hordeum spontaneum Koch. Evolution 56: 1403-1415.

Volis S, Mendlinger S, Turuspekov Y, Esnazarov U, Abugalieva S, Orlovsky N (2001a). Allozyme variation in Turkmenian populations of wild barley, Hordeum spontaneum Koch. Ann Bot 87: 435-446.
Volis S, Mendlinger S, Ward D (2002b). Differentiation in populations of Hordeum spontaneum along a gradient of environmental productivity and predictability: life history and local adaptation. Biol J Linn Soc 77: 479-490.

Volis S, Mendlinger S, Ward D (2004). Demography and role of the seed bank in Mediterranean and desert populations of wild barley, Hordeum spontaneum Koch. Basic Appl Ecol 5: 53-64.

Volis S, Shulgina I, Ward D, Mendlinger S (2003). Regional allozyme variation in wild barley, Hordeum spontaneum: adaptive or neutral? J Hered 94: 341-351.

Volis S, Yakubov B, Shulgina I, Ward D, Mendlinger S (2005). Distinguishing adaptive from non-adaptive genetic differentiation: comparison of $Q_{\mathrm{ST}}$ and $F_{\mathrm{ST}}$ at two spatial scales. Heredity 95: 466-475.

Volis S, Yakubov B, Shulgina I, Ward D, Zur V, Mendlinger S (2001b). Tests for adaptive RAPD variation in population genetic structure of wild barley, Hordeum spontaneum Koch. Biol J Linn Soc 74: 289-303.

Wagner DB, Allard RW (1991). Pollen migration in predominantly self-fertilizing plants: barley. J Hered 82: 302-304.

Willson MF (1993). Dispersal mode, seed shadows, and colonization patterns. Vegetation 107/108: 261-280.

Wright S (1943). Isolation by distance. Genetics 28: 114-138. 